\title{
Etiological and pathophysiological enigmas of severe coronavirus disease 2019, multisystem inflammatory syndrome in children, and Kawasaki disease
}

\author{
Jung-Woo Rhim, MD, PhD ${ }^{1}$, Jin-Han Kang, MD, PhD ${ }^{1}$, Kyung-Yil Lee, MD, PhD ${ }^{1,2}$ \\ ${ }^{1}$ Department of Pediatrics, The Catholic University of Korea College of Medicine, Seoul, Korea; ${ }^{2} J$ unglock Biomedical Institute, Daejeon, Korea
}

During the coronavirus disease 2019 (COVID-19) pandemic, a novel multisystem inflammatory syndrome in children (MIS-C) has been reported worldwide since the first cases were reported in Europe in April 2020. MIS-C is temporally associated with severe acute respiratory syndrome coronavirus 2 infection and shows Kawasaki disease (KD)-like features. The epidemiological and clinical characteristics in COVID-19, KD, and MIS-C differ, but severe cases of each disease share similar clinical and laboratory findings such as a protracted clinical course, multiorgan involvement, and similar activated biomarkers. These findings suggest that a common control system of the host may act against severe disease insult. To solve the enigmas, we proposed the protein-homeostasis-system hypothesis in that every disease involves etiological substances and the host's immune system controls them by their size and biochemical properties. Also, it is proposed that the etiological agents of $\mathrm{KD}$ and MIS-C might be certain strains in the microbiota of human species and etiological substances in severe COVID-19, KD, and MIS-C originate from pathogen-infected cells. Since disease severity depends on the amounts of inflammation-inducing substances and corresponding immune activation in the early stage of the disease, an early proper dose of corticosteroids and/or intravenous immunoglobulin (IVIG) may help reduce morbidity and possibly mortality among patients with these diseases. Corticosteroids are low cost and an analogue of hostorigin cortisol among immune modulators. This study's findings will help clinicians treating severe COVID-19, KD, and MIS-C, especially in developing countries, where IVIG and biologics supplies are insufficient.

Key words: COVID-19, Kawasaki disease, Multisystem inflammatory syndrome, MIS-C, Corticosteroid

\section{Key message}

- Severe cases of coronavirus disease, Kawasaki disease (KD), and multisystem inflammatory syndrome in children (MIS-C) share similar findings: a protracted clinical course, multiorgan involvement, and similar activated biomarkers.

- Here we propose etiological agents in $\mathrm{KD}$ and MIS-C as species in the microbiota and introduce a common pathogenesis through the protein-homeostasis-system hypothesis.

- Early proper dose of corticosteroids and/or intravenous immunoglobulin may help to reduce morbidity and mortality in these diseases.

\section{Introduction}

Coronavirus disease 2019 (COVID-19), caused by severe acute respiratory syndrome coronavirus 2 (SARS-CoV-2), is still spreading, and vaccination programs for eradicating the COVID-19 pandemic are being established around the word.

The accumulated epidemiological and clinical data of the characteristics of COVID-19 indicate that children are infected less frequently and experience milder symptoms than adults. However, a small proportion of healthy children and young adults suffer from severe pneumonia, which can progress to acute respiratory distress syndrome (ARDS), multiorgan failure, and death; the same can occur more frequently in older patients with underlying diseases. ${ }^{1,2)}$ In COVID-19, unresolved issues include the causes of severe pneumonia, cytokine storm and corresponding lymphopenia, species specificity, and the mechanism of damage to cells of multiple organs. ${ }^{3,4)}$

During the COVID-19 pandemic, a novel hyperinflammatory syndrome called multisystem inflammatory syndrome in children (MIS-C) or pediatric inflammatory multisystem syndrome temporally associated with SARS-CoV-2 (PIMS-TS) has been reported in large cities in Western countries since the first cases reported in April 2020.5-7) This disease might be associated with the epidemiological trend of COVID-19 in some countries, and laboratory results of polymerase chain reaction (PCR) or serologic IgG are positive for SARS-CoV-2 infection in the majority of affected patients. Patients with MIS-C manifest fever,

\footnotetext{
Corresponding author: Kyung-Yil Lee, MD, PhD. Department of Pediatrics, The Catholic University of Korea Daejeon St. Mary's Hospital, 64 Daeheung-ro, Jung-gu, Daejeon 34943, Korea 
gastrointestinal, mucocutaneous, cardiac symptoms and signs, and elevated inflammatory biomarkers. In May 2020, the World Health Organization (WHO), Centers for Disease Control and Prevention of the United States (US), and Royal College of Paediatrics and Child Health of the United Kingdom published guidance for the case definition for MIS-C or PIMS-TS. ${ }^{8-10)}$ The clinical and laboratory findings resemble some aspects of Kawasaki disease (KD), those of infectious diseases such as sepsis/toxic shock syndrome and acute severe COVID 19, and immune-mediated diseases such as macrophage activation syndrome (MAS). However, direct evidence of the relationship between MIS-C and SARS-CoV-2 infection is lacking, and its pathophysiology remains unknown.

$\mathrm{KD}$ is an acute febrile infection-related immune-mediated disease of childhood usually affecting children younger than 5 years of age. Although the etiological agent(s) have not been identified, $\mathrm{KD}$ might be triggered by substances produced in response to agent exposure. ${ }^{11)}$ The clinical course of KD is self-limited regardless of severity, and the majority of affected patients has an average fever duration of 10-11 days and recover from the disease without complications. ${ }^{12)}$ Clinical phenotypes and involved organs in KD vary among individuals, and some severely affected patients have prolonged fever and higher risk of complications such as coronary artery lesions (CALs) including giant coronary artery aneurysms. Some epidemiological and clinical factors, such as age predilection and geographic incidence, and the main affected target organs differ between $\mathrm{KD}$ and MIS-C. ${ }^{13)}$ Despite extensive studies over 5 decades after its emergence, the etiology and pathophysiology of $\mathrm{KD}$ remain to be elucidated.

Every disease has etiological substances eliciting inflammation and affecting clinical phenotype and target organ cell injury, although not all have been discovered. It is postulated that the main function of the host immune/repair systems is to control the toxic substances that target self-organ cells according to their size and biochemical characteristics (the protein-homeostasissystem [PHS] hypothesis). We previously explained the pathophysiology of the diseases, including COVID-19 and KD, through the PHS hypothesis. ${ }^{3,11,14,15)}$

Here we further discuss regarding some unsolved issues in pathophysiology, diagnosis, and treatment on COVID-19, as well as some etiological and pathophysiological aspects of MIS-C based on previous studies of KD under the PHS hypothesis.

\section{Epidemiology}

Since the COVID-19 pandemic is ongoing, the epidemiological characteristics of SARS-CoV-2 infection in children, including age distribution, rates of symptomatic infection and severe COVID-19 (or pneumonia), and the transmission role of children, remain to be investigated. Many studies performed in the early stage of the pandemic reported that children are less often infected and are more often asymptomatic or have milder disease than adults. ${ }^{16,17)}$ Since children draw less medical attention and are less likely to be tested, the detected infection rate in children could be lower than the actual infection rate. ${ }^{18)}$

Viruses specific to the human species, including human corona viruses (subtypes 229E, NL63, OC43, and HKU1) and human influenza viruses, have evolved with the species, and infections caused by these viruses occur every year via stable human reservoirs or carriers. ${ }^{19)}$ The viruses live harmoniously as part of the human microbiota but occasionally sacrifice some hosts, especially older persons. Thus, it is expected that the clinical severity of COVID-19 will become milder over time during or after the pandemic due to the appearance of variants that are more adapted to the human species. ${ }^{3)}$ The proportion of severe COVID-19 cases in children and young adults might be reduced over time. Four influenza pandemics occurred over the course of a century in 1917, 1959, 1968, and 2009 and the severity of pandemic influenza has decreased over time regardless of newly introduced virus subtypes. In the $2009 \mathrm{H} 1 \mathrm{~N} 1$ pandemic, we observed that approximately $2.5 \%$ of febrile patients with reverse transcriptase-PCR (RT-PCR) positivity had pneumonia and some of them had rapidly progressing pneumonia. Severe pneumonia cases were more common before the peak of the outbreak in Deajeon, Korea. ${ }^{20,21)}$

After first reported in European countries and the US, cases of MIS-C have been reported worldwide during the COVID-19 pandemic. ${ }^{22-24)}$ MIS-C affects children between 3 and 20 years of age (median age, 7-9 years) but, as with $\mathrm{KD}$ young adults can be affected as well. ${ }^{25)}$ The frequency of suspected MIS-C appears along with the epidemiological trend of COVID-19 outbreaks in some populations, but long-term epidemiological studies are needed to confirm these findings. There is a time gap of 2-6 weeks between the occurrence of MIS-C and the initial SARS-CoV-2 infection, suggesting that MIS-C is a postinfectious immune-mediated disease such as acute rheumatic fever (ARF) or postviral myocarditis. ${ }^{26,27)}$ Although MIS-C is a rare disease and resources are lacking in many countries, its incidence varies across populations. MIS-C is reportedly more common in Europe and the US than in East Asian countries including Japan, China, and Korea. In Europe and the US, children with African or Hispanic heritage tend to be affected more frequently than white children, ${ }^{6,7)}$ suggesting an association with racial, environmental, or socioeconomic factors.

Since KD has been studied for more than 50 years, its epidemiological characteristics are well-documented and provide a clue to its etiology. After the first report of KD in the early 1960s in Japan, the disease has appeared over 60 countries around the world. ${ }^{28)}$ Japan and Korea currently have the highest incidences of KD worldwide, 10-30 times higher than those of Western countries; the incidence in children aged $<5$ years was 359 per 100,000 children in 2018 in Japan, ${ }^{29} 202$ in 2017 in Korea, ${ }^{30)}$ and 19 in 2018 in the US. ${ }^{31)}$ Although KD is a new disease in East Asian countries, infantile polyarteritis nodosa, which might be a severe form of $\mathrm{KD}$, has been reported in Western countries since the late 19th century. ${ }^{32)} \mathrm{KD}$ was first reported in Asian countries 
in specific time periods: in the 1960s in Japan, the 1970s in Korea and Taiwan, the 1980s in China, and the 1990s in India and other economically developing Asian countries. This suggests that economic growth and westernization of these countries are associated with the emergence of KD. ${ }^{11,33)}$ In these countries, $\mathrm{KD}$ has the same age predilection of 6 months to 4 years as in Western countries and has become a nationwide endemic disease within 2 decades with a slowly increasing incidence after its first report. In larger cities in endemic countries, $\mathrm{KD}$ occurs throughout the year with slight monthly and annual case variations. Thus, the pattern of annual cases in a city could not match nationwide patterns, which suggests that $\mathrm{KD}$ occurs as outbreak pattern in large cities and not simultaneously in all cities of a nation. ${ }^{34)}$ On the contrary, the incidence of $\mathrm{KD}$ in Western countries is far lower than that in Asian countries and has plateaued during recent decades. ${ }^{31,35)}$ These unique epidemiological characteristics are not observed in any newly emerging infectious diseases, such as acquired immune deficiency syndrome, SARS, or COVID-19. Additionally, during this pandemic, the incidence of $\mathrm{KD}$ has been markedly reduced in Korea, and possibly in other East Asian countries (personal communications). Thus, KD and possibly MIS-C might not be associated with nationwide viral epidemics. The clinical characteristics of $\mathrm{KD}$, including no person-to-person transmission, antibiotic nonresponsiveness, and difficulty of detecting pathogens, indicated that KD might be an acute immune-mediated disease that develops after infection with unknown pathogen(s), while the pathogenesis of KD might be more similar that of postinfectious immune-mediated diseases such as ARF rather than that of infectious diseases such as scarlet fever. ${ }^{11)}$

Epidemiological changes have been observed in infectious diseases and infection-related immune-mediated diseases. Changes in the clinical severity of infectious diseases such as scarlet fever, bacterial endocarditis, and pandemic influenza have been well-documented in developed countries. ${ }^{36,37)}$ We also ob. served that $\mathrm{KD}$, acute poststreptococcal glomerulonephritis (APSGN), and Henoch-Schönlein purpura (HSP) have developed milder phenotypes over time in Korea. ${ }^{38-40)}$

Like KD, MIS-C might be associated with pathogen infection and environmental factors. However, it is unknown whether MIS-C can spread across populations like $\mathrm{KD}$ or will subside with or without the pandemic over time. Long-term studies are needed to determine the epidemiological characteristics of MIS-C.

\section{Clinical manifestations}

COVID-19, KD, and MIS-C are self-limiting diseases, although some patients experience a severe clinical course and complications. The natural courses of the diseases differ among individuals, and recovery depends on each individual immune status. Clinicians tend to focus on severe cases and disease complications, but it is necessary to understand the disease comprehensively as a complex of various clinical phenotypes from asymptomatic/mild cases to severe potentially fatal cases.

Manifestations of COVID-19 range from asymptomatic infection to severe fatal outcomes. A small proportion of patients experience pneumonia, and a smaller proportion of patient with pneumonia experiences disease progression or complications, such as rapidly progressive pneumonia, ARDS, and/or other critical organ involvements. Although the main target organ is the lungs, other organs such as the skin, musculoskeletal system, heart, liver, kidneys, nervous system, hematologic system, and gastroenteric system can be affected. ${ }^{41,42)}$ Extrapulmonary manifestations caused by cytokine storm can occur simultaneously with acute infection, but the majority of patients with SARSCoV-2 infection complain of organ-specific diseases such as encephalopathy, myositis, carditis, and nephritis after the symptoms and signs of the initial infection subside. The findings have been observed in patients with other respiratory pathogen infections, including influenza and Mycoplasma pneumoniae (M. pneumoniae) infection, ${ }^{43,44)}$ suggesting that postinfectious immune reactions are associated with extrapulmonary diseases.

Patients with KD manifest acute-onset fever and gradually appearing diagnostic signs, including bilateral conjunctival injection, oral mucosal changes such as red fissured lips and strawberry tongue, skin rash, edema of the hands and feet, and cervical lymphadenopathy. ${ }^{45,46)}$ These diagnostic signs appear in the majority of the patients, but they do not appear in all patients or simultaneously during the acute stage of KD. The primarily affected cells are those of the medium sized arteries, especially the coronary arteries, but other organ cells can be involved during the acute illness as well as in severe COVID-19 and MIS-C. Rare clinical entities include carditis, arthritis, uveitis, gall bladder hydrops, retropharyngeal pseudo-abscess, MAS, shock syndrome, and neurological or pulmonary involvements. ${ }^{4-49)}$

Patients with MIS-C present with a high fever, gastrointestinal symptoms, KD-like signs, and shock syndrome with or without cardiac dysfunction. The majority of patients present with gastrointestinal symptoms such as abdominal pain, diarrhea, and vomiting, mimicking acute gastroenteritis or mesenteric lymphadenitis in large case series (53\%-100\%). ${ }^{6,750,51)} \mathrm{In}$ addition, systematic review studies reported that $\mathrm{KD}$-like features are observed in many patients; skin rash in $42 \%-58 \%$, oral mucosal changes such as red fissured lips and strawberry tongue in 23\%-59\%, conjunctival injection in 40\%-51\%, edema of the hands and feet in $15 \%$, and cervical lymphadenitis in 4\%-17\%. ${ }^{52)}$ Cardiovascular abnormalities, including myocardial dysfunction, pericarditis, valvular regurgitation, and coronary artery ectasia or aneurysms, are reported in 34\%-82\% of patients. Hypotension and/or shock are observed in 28\%-61\% of patients. Respiratory symptoms such as cough, sputum, and tachypnea are observed in a relatively small proportion of patients. Despite similar clinical signs between MIS-C and KD, shock syndrome, cardiac involvement, and severe cases requiring inotropic support are observed more commonly in MIS-C than in KD..$^{52-54)}$ These findings suggest that patients with MIS-C show various clinical symptoms and signs and can be diagnosed in various conditions 
including acute infectious diseases such as septic conditions and severe COVID-19, and other immune-mediated diseases such as $\mathrm{KD}, \mathrm{KD}$ shock syndrome, MAS, and systemic juvenile idiopathic arthritis (JIA). At presentation, respiratory symptoms are prominent in severe COVID-19 cases, while gastrointestinal symptoms and/or cardiac involvement are common in MIS-C.

\section{Laboratory findings}

Most infectious diseases and immune-mediated diseases, including COVID-19, KD , and MIS-C, have a self-limiting clinical course, even in cases of complications. During the self-limiting clinical course of $\mathrm{KD}$, the intensity of systemic inflammation in the acute febrile stage of $\mathrm{KD}$ gradually increases and reaches the peak stage. After the peak the inflammation gradually decreases and the disease enters the convalescent stage through the host's immune system. ${ }^{11)}$ We observed that the C-reactive protein (CRP) level and neutrophil count are highest and the levels of albumin, hemoglobin, and lymphocyte are lowest at mean 6th day of fever onset as the peak stage of inflammation. ${ }^{55,56}$ In addition, the platelet count, immunoglobulin (IgG, IgA, and IgM) levels, and total protein level begin to increase at the inflammation peak stage, suggesting that these parameters are involved in the recovery reaction in $\mathrm{KD} .{ }^{57)}$ Therefore, it is a reasonable assumption that host immune reactions preceding the peak of the inflammatory process are associated with tissue cell injury during the initial hyperimmune reaction such as cytokine storm, while immune reactions following the peak stage mediate tissue cell repair. As self-limited diseases, the clinical course of COVID-19 pneumonia and MIS-C might have similar pathways to that of $\mathrm{KD}$, although clinical phenotypes vary among individuals. During systemic inflammation processes, the severity is reflected by the laboratory parameter levels, including white blood cell (WBC), lymphocyte and neutrophil differentials, CRP, albumin, hemoglobin, platelet, immunoglobulins, and other biomarkers such as cytokines and chemokines as well as various biochemical indices of organ involvement such as troponins, creatinine, lactic dehydrogenase, and bilirubin. Many studies have reported risk factors of CALs or intravenous immunoglobulin (IVIG) nonresponsiveness in $\mathrm{KD}^{58,59)}$ Indeed, severely affected patients have a prolonged fever duration, higher or lower biomarker values, and higher rates of IVIG-nonresponsiveness and complications such as CALs in KD as well as possibly MIS-C and severe COVID-19.

Research has examined various biomarkers to evaluate the characteristics of severe COVID-19, KD, and MIS-C. Since patients severely affected with these diseases have a systemic hyperinflammation state with potentially multiorgan involvement, almost all biomarkers associated with the innate immune system, adaptive immune system, and various inflammatory pathways are activated. The kinds of activated biomarkers can differ according to the organs affected, but activated major biomarkers of inflammation, including a WBC change with lymphopenia, elevated values of CRP, erythrocyte sedimentation rate, procalcitonin, and proinflammatory cytokines, including interleukin (IL)-6, IL-1 and tumor necrosis factor- $\alpha$ (TNF- $\alpha$ ), and lower values of albumin, hemoglobin, and sodium, are commonly noted. These findings suggest that there is a common mode of pathophysiological mechanisms across these severe diseases.

To study the role of biomarkers, understanding the disease progressing processes is necessary, and a serial biomarker examination at each stage is crucial. Repeated examinations of proper inflammatory biomarkers, including WBC, CRP, albumin, and hemoglobin, during the early febrile stage is helpful for assessing the stage of disease progression in patients, and for ensuring the early diagnosis and proper treatment in $\mathrm{KD}$ and other infectious diseases such as severe $M$. pneumoniae pneumonia and COVID-19.56,59,60)

\section{Etiology}

Although the etiologic agent of COVID-19 is SARS-CoV-2, the immunopathogenesis of organ cell injury in SARS-CoV-2 infection as well as other pathogen infections remains unknown. The major critical complication of COVID-19 is ARDS which is responsible for long-term morbidity and mortality in any pneumonia caused by infectious agents, including SARSCoV, SARS-CoV-2, influenza viruses, and bacteria. However, pneumonia and ARDS is caused by noninfectious insults including blunt chest contusion, gastric content aspiration, multiple trauma, pancreatitis, severe burn, toxic material inhalation, and amniotic fluid embolism. ${ }^{61,62)}$ These findings suggest that the etiologic substances of pneumonia and ARDS could be related to the substances derived from the host cells by physical injury or other conditions. In addition, animal studies and postmortem pathological studies of severe viral pneumonia revealed that few intact virions in extensively injured organ tissues and only occasional PCR or histochemical antibody positivity. ${ }^{63-65)}$ Majority of affected subjects might be PCR negative in the blood even in severe cases. Thus, it is a reasonable assumption that the etiological substances in pneumonia and ARDS in viral infections are produced by certain pathogen-infected cells rather than the pathogen itself. If SARS-CoV-2 is responsible for acute lung injury, researchers should identify the pathogens via lung tap and/or pleural effusion instead of those from the upper or lower respiratory tracts such as nasopharyngeal swab or bronchial lavage fluid, and through a culture method rather than PCR assay.

The epidemiological and clinical characteristics of $\mathrm{KD}$ suggest its association with one or more undetermined pathogens. Regarding its etiology, various pathogens, including viruses, bacteria, mycoplasma and rickettsia, and environmental factors such as environmental toxins and allergens have been suggested. ${ }^{46)}$ However, the pathogen(s) of $\mathrm{KD}$ should satisfactorily explain its epidemiological and clinical characteristics discussed in the above sections.

Although normal flora, including bacteria and viruses, live 
with the host interdependently, they can invade the host and elicit infectious diseases and postinfectious immune-mediated diseases. Accordingly, most etiological agents in infectious diseases, including urinary tract infection (UTI), otitis media, and pneumonia, originate from normal flora of the same species. $\left.{ }^{66}\right)$ Since most of the strains in microbiota cannot be identified by current culture methods, new methods using pathogen genomic analysis such as high-throughput sequencing have been introduced to diagnose infections. ${ }^{67)}$ Since various bacterial genomes are always detected in the blood of healthy controls, the methods are not considered reliable, likely bacterial PCR assays in lower respiratory tract infections. However, it is possible that true pathogens derived from normal flora could be considered false positive or due to sample contamination. Furthermore, some strains of microbiota such as Lactobacillus in breast milk might be related to the strains in the intestines. ${ }^{68)}$ Therefore, it is possible that some species of microbiota in the blood might not be harmful to the host and that externally introduced pathogens from other species can adapt to human species over time through unknown species-specific relationships between pathogens and the host. Childhood immune-mediated diseases, including JIA, HSP, and type I diabetes, are associated with dysbiosis of some strains in microbiota. ${ }^{69,70)}$ Also, many researchers have studied in the relationships between dysbiosis of the normal flora and $\mathrm{KD} .{ }^{71,72)}$ We have proposed that the etiological agents of $\mathrm{KD}$ are certain strains in the microbiota of human species based on the epidemiological and clinical characteristics of $\mathrm{KD},{ }^{11,33,73)}$

The susceptibility of a disease, especially an immune-mediated disease, has been explained by genetic and environmental factors. Variations in incidence across populations and in ages between KD and MIS-C might be associated with genetic or environmental factors. Many studies reported the genes that are associated with KD susceptibility and/or severity. ${ }^{74)}$ However, patients with KD or MIS-C in different populations manifest near-identical clinical manifestations with similar complication rates. Further, the immune functions against the insults of $\mathrm{KD}$ or MIS-C pathogen infections might be the same in all children across populations. The results of genetic studies of $\mathrm{KD}$ and other immune-mediated diseases have limited clinical implications due to no definitive genetic markers of diagnosis and some genetic traits not being reproducible in populations.

It is well-known that the distribution of microbiota in humans varies according to ages and among ethnic groups. ${ }^{75,76)}$ Strains in the microbiota can be changed by environmental factors such as diet and antibiotics. ${ }^{77,78)}$ The infection of normal flora is elicited by colonization first and followed by invasion of colonized pathogens into the host. ${ }^{73)}$ Because pathogens in normal flora spread via colonization, a new disease such as $\mathrm{KD}$ takes a long time to widespread and is influenced by the ages of children and ethnicity. The possibility in $\mathrm{KD}$ agent(s) invasion into the host may be similar in individuals in populations. Thus, the different incidence and age distribution, and different clinical manifestations of KD, MIS-C, and other childhood immunemediated diseases might be associated with the colonization states of pathogens in the populations. Certain diseases such as UTI, rheumatoid arthritis, and systemic lupus erythematosus (SLE) show a marked female predominance. ${ }^{66)}$ It is postulated that the pathogens in these diseases are associated with their colonization state of the female urogenital tract.

The reason for the emergence of MIS-C remains to be elucidated. It is possible that SARS-CoV-2 infects various cells in the host (upper respiratory cells vs. other organ cells such as lower respiratory cells or regional lymph node cells). Each infected cell might produce different substances that are responsible for different clinical manifestations and incubation periods among individuals. ${ }^{3)}$ However, there have been few reports of viral infections that induce acute postinfectious systemic inflammation as in MIS-C. ARF is a representative of postinfectious systemic inflammation caused by group A beta hemolytic streptococci (GAS) and other bacterial species. The symptoms of ARF and APSGN appear after the initial pharyngitis or pyoderma subsides with a time gap of 2-6 weeks. ${ }^{79)}$ The GAS are now considered normal flora since there are many healthy carriers among children with occasional pharyngitis. ${ }^{80)}$ Although GAS is a known extracellular pathogen, some strains can reside in host cells. ${ }^{81)}$ Thus, it is possible that GAS or other pathogens residing in certain cells might be associated with postinfectious diseases like ARF, APSGN, rhematic heart diseases, and postinfectious glomerulonephritis. Intracellular bacterial infections, such as typhoid fever and tuberculosis, can produce a variety of inflammation-inducing substances versus viral infections during intracellular replication processes since bacteria have far more genes for pathogenic proteins and peptides.

On the other hand, it is possible that environmental changes caused by the COVID-19 pandemic such as lock down policies are associated with the appearance of MIS-C. During the early stage of the pandemic, lock down policies affected the eating habits and lifestyles of children and adults in many countries..$^{82,83)}$ While staying home, some people experience a changed diet for a long period of time, causing transient dysbiosis in family members including children. Due to competition among strains of the same species in microbiota, the dysbiotic strains (MIS-C pathogens) might easily invade the host during or after the colonization process. The colonized MIS-C pathogens could spread to other children. Given the epidemiological characteristics such as the different incidence among ethnic groups and predominance in older children, the etiology of MIS-C might be certain strains in the microbiota of human species as with KD. It is possible that pathogens differ between KD and MIS-C and that infected host cells produce different substances but can produce some substances responsible for similar clinical signs during the diseases processes.

\section{Pathophysiology}

Explanations of the unsolved issues about COVID-19 are based on hypotheses from clinical, epidemiological, pathologi- 
cal, and experimental observations. Because the causes of host cell injury in various infectious diseases and infection-related immune-mediated disease have been explained by the pathogens themselves, current immunological concepts have limited ability to explain the enigmas in COVID-19, KD, and MIS-C. The host's immune system reacts not only to smaller substances from the infectious agents, including toxins and pathogenassociated molecular patterns (PAMPs), but also to those from the injured or infected host cells including damage-associated molecular patterns (DAMPs) and intracellular substances such as pathogenic proteins, pathogenic peptides, and smaller biochemical materials. ${ }^{84,85)}$ Indeed, adaptive immune system activation, including that of helper $\mathrm{T}$ cells and cytotoxic $\mathrm{T}$ cells, viral neutralization, and antibody-dependent cytotoxicity, as well as innate immune system activation, including that of phagocytes (neutrophils and macrophages), toll-like receptor (TLR)-associated reactions, and the complement system, are also involved in the appearance of clinical manifestations in cases of severe COVID-19, KD, and MIS-C. In addition, the coagulation system, including platelets and coagulation-associated proteins, and other metabolic systems can be affected by the insult of a hyperinflammatory disease state. ${ }^{86,87)}$

Every organ-specific cell has its own receptors for communicating with other cells, and all physiological and pathological phenomena at the cellular level are performed through the binding of substances to the receptors on or in cells. Every disease has etiological or inflammation-inducing substances that can bind the receptors on target organ cells. The sizes of such substances range from extremely small, such as carbon monoxide, nicotine, and chemicals (or drugs), to larger, such as viruses, bacteria, and parasites. Even extremely small substances such as elements and monoamines have an affinity to receptors expressed on or in host cells. ${ }^{88,89)}$ On the other hand, the etiological substances can be divided by their biochemical properties such as protein versus nonprotein. Thus, a variety of inflammation-inducing substances exist in pathologic lesions in COVID-19, KD, MIS-C, and other diseases although their identification remains for future studies.

The PHS hypothesis propose that the host's immune system reacts to these substances according to substance size and biochemical properties. Briefly, the adaptive immune system controls pathogenic protein substances; $B$ cells control pathogenic proteins through antibody production, while $\mathrm{T}$ cells control pathogenic peptides through T-cell receptor (TCR)-related reactions. The innate immune system controls larger complex substances such as intact viruses, bacteria, and apoptotic bodies through phagocytes, while TLRs-associated reactions, natural antibodies, complements, and unidentified immune protein systems control smaller nonprotein substances such as polysaccharides, viral RNAs, pathogenic smaller peptides, and monoamines. $3,11,14,15)$ Pathogens (viruses and bacteria) in the circulation can be removed easily by phagocytes; thus, pathogens themselves are not a direct cause of acute lung injury or other organ injury in COVID-19, $\mathrm{KD}$, or MIS-C.

The pathophysiology of COVID-19, KD, MIS-C and other infection-related autoimmune disease are possibly as follows. There is focus on each infectious disease and infection-related immune-mediated diseases, which include etiological substances responsible for disease-onset. On occasion, colonized SARS$\mathrm{CoV}-2$ viruses, $\mathrm{KD}$ agents, or MIS-C agents invade the host via unknown events, possibly the hematogenous route. The invaded pathogens attach to certain host cells, enter them, and create a focus. A majority of patients infected with KD or MIS-C pathogens may be asymptomatic as with COVID-19, and the diseases are self-limited if the amount of the substances from the focus is small and controlled as a localized inflammation. The focuses in COVID-19, KD, and MIS-C contain replicated pathogens, byproducts of the pathogen (toxins and fragments of DNA, RNA, and proteins), PAMPs, and other numerous intracellular materials including DAMPs, pathogenic proteins, pathogenic peptides, and other smaller biochemical materials. The focus in each disease may be established during the incubation period. During or after recovery from the initial pathogen infection, each disease develops when substances in the focus spread abruptly into systemic circulation. The pathogenic substances in the focus bind to target organ cells, and corresponding immune reactions against the substances are activated, and clinical symptoms and signs begin to manifest. During this process, a cytokine imbalance such as cytokine storm is associated with target cell injury. The substances produced by the injured target cells caused by the initial immunological insult can induce further inflammation if released into the systemic circulation or near local lesions. Furthermore, the initial insult can damage to the barrier cells and induce a secondary bacterial invasion. After the establishment of specific immune cells by TCR and B-cell receptor (BCR) recombination, the pathogenic proteins and peptides are effectively controlled and the inflam. mation ceases (Fig. 1).

Clinical symptoms and signs differ among COVID-19, KD, and MIS-C although some overlap. Considering the main symptoms of the diseases, the target cells are likely lung cells in severe COVID-19, coronary artery cells in KD, and gastroenteric and/ or cardiac cells in MIS-C although other cells can be affected. Since the severity of ongoing diseases is associated with amounts of substances with corresponding immune reactions at the early stage, abrupt spread of excess substances can induce cytokine imbalance such as cytokine storm, which is related to initially activated nonspecific adaptive immune cells and innate immune cells. It is believed that cytokine storm is associated with the target cell injury although the mechanisms are unknown. ${ }^{90,91)}$ Furthermore, like extensive lung injury in ARDS, there are rapidly progressive organ-specific diseases that can affect near whole organ such as delated cardiomyopathy, fulminant hepatitis, necrotizing pancreatitis, rapidly progressive glomerulonephritis, acute adrenal necrosis, extensive epidermolysis, and acute encephalopathy. ${ }^{62)}$ Therefore, early control of target organ cell injuries from initial hyperactive immune reactions performed by nonspecific adaptive and/or innate immune cells is crucial for reducing morbidity and preventing pneumonia progression in 


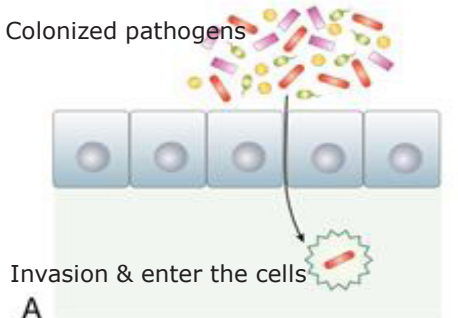

A

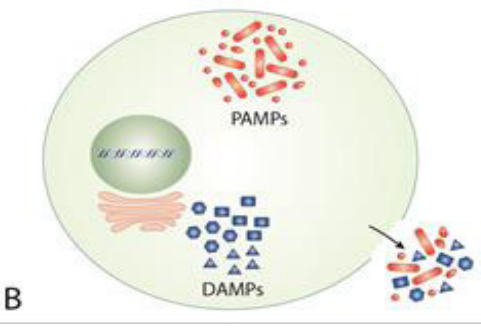

Infected cells: the focus

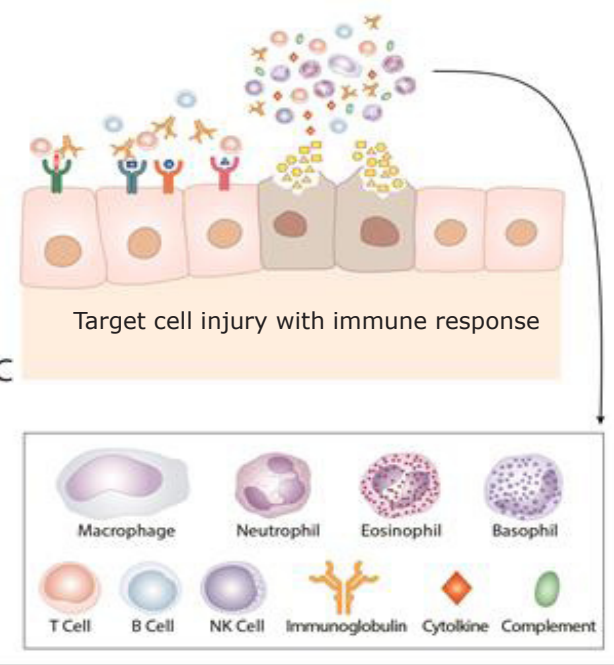

Immune components against etiological substances

Fig. 1. A common pathogenesis of coronavirus disease, Kawasaki disease (KD), and multisystem inflammatory syndrome in children (MIS-C). On occasion, colonized severe acute respiratory syndrome coronavirus 2, KD agents, or MIS-C agents invade the host and enter the cells (A). During the incubation period, the pathogens replicate within cells and establish a focus elsewhere in the host. The focus of each disease contains not only pathogen-origin substances, including replicated pathogens, pathogen-associated molecular patterns, toxins and other byproducts of pathogens from the replication process, but also host cell-origin substances, including damage-associated molecular patterns, pathogenic proteins, pathogenic peptides, and other immune substances acting against invading pathogens such as interferons and immune peptides, which can be toxic to other host cells if realized (B). These substances can spread via the systemic or local circulation and bind to the target cells. The host's immune system begins to act for control of these substances and initiates inflammation elsewhere at the target cells, and clinical symptoms and signs begin to appear. The abrupt spread of excess amounts of these substances induces cytokine storm, which are related to initially activated nonspecific adaptive immune cells and innate immune cells, and cytokine imbalance is responsible for the target cell injury. The subsequent substances derived from injured target cells or those produced during initial immune reactions induce further inflammation resulting in neighboring cell injury and secondary bacterial invasion (C). After the establishment of specific immune cells by the T-cell receptor and B-cell receptor recombination, the pathogenic proteins and peptides are effectively controlled, and inflammation ceases. The immune systems of some patients with coronavirus disease 2019 (COVID-19), KD, or MIS-C are unable to induce specific clones against pathogenic proteins or peptides derived from injured cells, thus, the ongoing activation of nonspecific adaptive immune cells and/or innate immune components is responsible for chronic immune-mediated diseases and complications.

patients with COVID-19 pneumonia as well as those with severe KD and MIS-C.

Although most patients with COVID-19 pneumonia, KD, and MIS-C recover from the disease, some experience long-term morbidity of affected organ(s) or other postinfectious immunemediated organ diseases. In the PHS hypothesis, patients with these conditions have an improper immune response, especially of the adaptive immune system, since pathogenic peptides and pathogenic proteins should be controlled by $\mathrm{T}$ cells and B cells, respectively. The adaptive immune system of the patients in these conditions might have a defect in genes of recombination of TCR or BCR. The T cell or B-cell clones against the substances derived from initially or secondarily injured cells might be lately produced or cannot be produced. Thus, persistent activation of nonspecific adaptive and/or innate immune systems can be responsible for ongoing inflammation and target cell injury in chronic autoimmune diseases.

The PHS hypothesis provides new interpretations on unsolved issues in COVID-19 and other diseases. The theory of antibody-dependent enhancement has been proposed to play a part in pathogenesis of viral infections, including dengue fever and COVID-19.92) The patients with pre-existing or higher pathogen-specific antibodies seem to show more severe clinical manifestations. The phenomena might be explained that the substances elicit exacerbation of clinical symptoms in the conditions is not associated with entrance of viruses into the cells, i.e., not viruses themselves, and etiological substances are not controlled by virus-specific antibodies. The etiological or inflammation-inducing substances might not be pathogenic proteins derived from viruses, but other substances including pathogenic peptides or other pathogenic proteins from injured or infected host cells.

The vaccination programs against COVID-19 are ongoing around the world. Various vaccines have been developed based on the mRNA of surface proteins of the virus or killed virus. The vaccines are designed to produce antibodies against SARS$\mathrm{CoV}-2 .{ }^{93)}$ Several studies have reported that vaccinees are infected less frequently and the vaccines are effective at limiting the spread of COVID-19. ${ }^{94)}$ However, it is unknown whether vaccinees can avoid severe pneumonia and other organ cell injury 
since pneumonia and other organ cell injury in viral infections might not be caused by viruses themselves. Furthermore, a B-cell clone and a T-cell clone are produced against a pathogenic protein and a pathogenic peptide, respectively, and they do not react to whole virion as a large complex of proteins. Thus, immune status of the host is dependent on not only antibodies, but other unidentified immune materials are also responsible for protection of the disease and attenuation of clinical symptoms.

Some researchers observed that antibody responses to SARSCoV-2 were different between children and adults with severe COVID-19. ${ }^{95,96)}$ A study reported that compared to adults, the low level of anti-N antibodies was observed in both children with MIS-C and those without. ${ }^{95)}$ However, it is believed that immune responses to viruses are identical in children and adults. It is possible that the amounts of substances such as byproducts or fragments of the viruses in the focus are different in mild patients and severe patients. Also, the finding suggests that the inflammation-inducing substances in MIS-C are not associated with viral-origin substances but other substances in infected cells.

\section{Diagnosis}

Rapid diagnosis of COVID-19, KD, and MIS-C is crucial to developing preventive and treatment options for public health and patient care. For rapid diagnosis of COVID-19, PCR assays and rapid antigen detection tests are introduced from the early stage of the pandemic. ${ }^{97)}$ Although PCR assays are used in clinical fields, there are some confounding factors. The result of PCR assay is influenced by disease stage, age of the patients, sampling site, causative strain variants, and the technical errors. ${ }^{98)}$ Furthermore, PCR assay is not a confirmative diagnostic method in many infectious diseases because the assay detects not only whole virions but also fragments of viruses derived from infected upper respiratory cells. Accordingly, a PCR positive result does not specify the infectivity of the disease and cannot determine the viral cause of systemic inflammation in COVID-19 and other infectious diseases. Indeed, some pneumonia patients with SARS-CoV-2 infection, especially lately presented patients or patients infected with variant strains, can show PCR negative at presentation. ${ }^{99)}$ The negative findings could be due to specimen quality and collection method, but it is possible that viral load is low or absent, meaning that the virus itself is not a direct cause of acute lung injury, as shown in other respiratory infections such as M. pneumoniae pneumonia. ${ }^{60,100)}$ On the other hand, longterm carriers of SARS-CoV-2 have been identified during the COVID-19 epidemic. Thus, carriers with pneumonia caused by other pathogens can be diagnosed with COVID-19 (false PCR positive). Sensitivity and specificity studies of PCR assays have been performed based on subjects with clinical symptoms, but there are few studies based on comparison with the results of serologic tests. The earlier PCR assays might be less sensitive to emerging variants of SARS-CoV-2.

In infectious diseases, including SARS-CoV-2 infection as well as in influenza virus and M. pneumoniae infection, pathogenspecific IgM antibodies are produced first, and then specific IgG and IgA antibodies follow. ${ }^{101)}$ Also, there is a time gap of several days or longer between the onset of symptoms such as fever, sore throat, myalgia and pneumonia and the appearance of pathogenspecific IgM and IgG antibodies. Thus, patients who present in the early stage of disease tend to show a higher rate of negative or lower titer of pathogen-specific IgM and IgG. Accordingly, a systemic review reported that pooled results for $\operatorname{IgG}$, IgM, and IgA antibodies and all antibodies showed low positivity during the first week since onset of symptoms (all less than 30\%), rising in the second week (72\%) and reaching their highest values in the third week (91\%). ${ }^{102)}$ The serological changes may appear in all infected patients, from the asymptomatic to those with severe infections although the extent of immune reaction and duration of antibody detection vary in individuals. However, there are few studies on kinetics of antibodies of all infected patients including asymptomatic patients in COVID-19 and other virus infections. ${ }^{103)}$ Patients with severe pneumonia in Middle East respiratory syndrome coronavirus infection and $M$. pneumoniae infection tend to have a longer time to seroconversion compared to those with mild pneumonia. ${ }^{104,105)}$ Also, it was reported that severe COVID-19 patients might have a delayed detection of nucleocapsid antibody. ${ }^{106}$ Since majority of subjects in the serological studies are admitted patients with severe COVID-19, it is possible that patients with more severe pneumonia are more lately seroconverted, suggesting that pathogen itself might not be direct inflammation-inducing substances in the early stage of severe COVID-19 and other pathogen infections.

During the pandemic, numerous serologic tests, including enzyme-linked immunosorbent assay and chemiluminescent immunoassay, have been introduced and tested. ${ }^{107)}$ Coronaviruses have 4 structural proteins: the spike protein (S), the nucleocapsid $(\mathrm{N})$, the envelope protein $(\mathrm{E})$, and the membrane protein $(\mathrm{M})$ : The serologic diagnostic kits use one of these proteins especially $\mathrm{S}$ proteins or $\mathrm{N}$ protein, as a target antigen, because of low sensitivity of whole virion particle as antigen. While the positive rates in detecting IgM and IgG vary across serologic methods since the used antigens are different in each kit and assay. ${ }^{106,108)}$ In addition, sensitivity of $\operatorname{IgM} / \operatorname{IgG}$ in some kits could be changed along with appearance of the variants of SARS-CoV-2.

It has been recommended that paired specific IgG serologic tests 2 to 4 weeks apart is needed to confirm a pathogen infection including SARS-CoV-2 infection. ${ }^{109)}$ Although this policy is difficult in selecting patients and clinical practice, only serial serologic tests for detecting seroconversion or increasing titer of IgM/IgG have been approved as confirmatory tests in infectious diseases.

In respiratory infections, including human coronavirus infection, influenza, and M. pneumoniae infection, nasopharyngeal viral load is highest in the first week and declined thereafter, but clinical course of the disease is not associated with viral load. ${ }^{103,110)}$ Furthermore, severe pneumonia patients tend to 
have a late seroconversion as previously discussed. It is possible that clinical improvement might begin at the time when immune status of the host, including antibodies to the substances derived from injured cells and pathogen-derived antigens, is established against the insults of the infections. Thus, identification of certain specific antibodies, not virus neutralizing antibodies, might be a prognostic factor for recovery from the disease.

The diagnosis of $\mathrm{KD}$ and MIS-C is dependent on the clinical signs and laboratory indices. Although MIS-C appears to be associated with SARS-CoV-2 infection, evidence of current or past SARS-CoV-2 infection (RT-PCR or serology) is reportedly $58 \%$ of the reported MIS-C cases. ${ }^{53)}$ This suggests that many patients with MIS-C are not associated with SARS-CoV-2 infection or there are mild cases with less immune reaction to the virus. The true infection rate of SARS-CoV-2 is unknown in pediatric populations, but it is expected that most children eventually will be infected with SARS-CoV-2 over time, as one of human species-specific viruses. There are many asymptomatic patients and healthy carriers after infection who will serve as reservoirs for continued spread of SARS-CoV-2 during and after the pandemic. Since colonization does not mean a 'systemic infection' but could be regarded as a localized infection, colonization of SARS-CoV-2 during the COVID-19 epidemics occur at similar rates between MIS-C patients and healthy children. The prevalent rates of SARS-CoV- 2 colonization in the MIS-C group and control group might be influenced by the epidemic state in localized regions where MIS-C outbreak occurs. Thus, further epidemiological studies on both groups are needed. As previously mentioned, there is no standard serologic method and antigen for SARS-CoV-2 infection. In addition, high levels of endogenous components, including proteins, lipids, or antibodies, in tested sera can affect serologic results. ${ }^{111)}$ It is possible that sera from severe MIS-C cases contain substances that can be cross-reactive IgG positive. Thus, it should be confirmed that the kit used for IgG is specific only for SARS$\mathrm{CoV}-2$ or can detect cross-reactive antigens from other coronaviruses, or other substances from insults of MIS-C. A comparative study using control groups of the same ages and/or a follow-up study for serological IgG tests in MIS-C are needed. A single RT-PCR and/or anti-pathogen IgG (even IgM) tests does not qualify as a confirmatory test for diagnosis of an infection of SARS-CoV-2 in MIS-C.

\section{Treatment}

Since the severity of the diseases is dependent on the amounts of inflammation-inducing substances and corresponding immune activation during the early course of the disease, early treatment, as soon as possible, can result in early recovery from the diseases.

During the pandemic, many drugs for patients with severe COVID-19 have been tested in randomized controlled studies, but few have been shown effective for improving mortality.
Since the pathogenesis of acute lung injury in viral pneumonia is associated with hyperactive immune reaction of the host, especially in immune-competent previously healthy patients, immune modulators have been used. Corticosteroids such as dexamethasone and methylprednisolone have been reported to be effective in reducing mortality of patients with severe COVID-19. ${ }^{112,113)}$ Also, many study groups have reported that treatment with antivirals, convalescent plasma, biologics targeting IL-1, IL- 6 , and TNF- $\alpha$, and other anti-inflammatory drugs has been effective in severe COVID-19 patients to reduce morbidity and clinical severity of the disease. ${ }^{114)}$

The guidance by WHO on treatment of COVID-19 has not recommended use of corticosteroids since before its declaration of the pandemic and now is recommend use for patients with severe COVID-19 only. ${ }^{115,116)}$ However, some patients with COVID-19 pneumonia especially in immune-competent groups experience a rapidly progressive pneumonia and ARDS within 1-2 days after fever onset, while pneumonia progression is slow and obscure, and pneumonia itself regardless of severity might be a risk factor on ARDS and mortality in older patients with underlaying conditions. ${ }^{3)}$ Furthermore, the effect of corticosteroids on viral pneumonia, including influenza and SARS, remains inconclusive due to many confounding factors; the timing, dose, schedule of corticosteroid therapy, and the selected subjects differed across study groups. ${ }^{117,118)}$

In contrast to children, adult subjects in COVID-19 studies include patients with a wide range of ages and various immune statuses. Old adult patients with underlying diseases should be regarded as immunologically incompetent subjects because some underlying diseases are controlled by the immune system of individual patients. ${ }^{3,20)}$ Older patients with underlying conditions have shown a higher risk of mortality with any infectious diseases or events. Not only COVID-19, but also seasonal influenza, common colds, bacterial outbreaks such as Escherichia coli, and food aspiration can cause severe pneumonia and/or organ failure in underlying organ diseases. Because the main causes of death are related to loss of function of organ(s) in underlying conditions and the immune status of the patients, mortality, especially long-term mortality in COVID-19 is associated more strongly with the immune status of the patients rather than SARS-CoV-2 infection or other infections. ${ }^{20)}$ Furthermore, since the progression of pneumonia in COVID-19 is caused by an initial hyperimmune reaction, outcomes of severe COVID-19 might be associated with the duration of disease-onset at presentation and the initiation time of immune modulators such as corticosteroids.

To determine the effectiveness of immune modulators for severe COVID-19 such as ARDS, researchers should divide the subjects into at least 2 groups such as an immune-competent group composed of healthy older children and younger adults and an immune-incompetent group including older patients with underlying diseases and patients with immune-compromised state. Also, the subject could be divided into different age groups such as $<40$ years, $41-65$ years, and $>66$ years. The subjects 
should be analyzed according to the time of disease-onset such as early ARDS (i.e., in the inflammatory stages of exudation/proliferation) versus late ARDS. Moreover, since the severity of viral pneumonia is dependent on the amounts of inflammation-inducing substances in the early stage and the effect of corticosteroids is dose-dependent, the initial dose of corticosteroid and the schedule of treatment could be determined on an individual basis. Despite different clinical manifestations in each group, the effectiveness of the drugs and characteristic of the diseases are defined more clearly through a reasonable study plan. We have recommended early preemptive immune modulators, especially corticosteroids and/or IVIG, and proper treatment modality, which is consist of early, enough dose of corticosteroids based on severity of the disease, and short-term use with rapid tapering. The rationale of this treatment modality is based on the PHS hypothesis and our experience with influenza pneumonia, acute bronchiolitis, and M. pneumoniae pneumonia. 3,62,63,119-121)

For treatment of KD, single high-dose IVIG $(2 \mathrm{~g} / \mathrm{kg})$ has been established as a standard based on the results of controlled studies. ${ }^{46)}$ This treatment is effective to induce rapid clinical improvement (defervescence) and reduction of some laboratory parameters such as CRP and WBC within 24-48 hours after initiation of IVIG infusion in a majority of patients. However, some severely affected patients show a persistent fever, sustained or elevated CRP and WBC, and a higher risk of CALs. For these patients, pediatricians have used various regimens including IVIG reinfusion, methylprednisolone pulse therapy $(10-30 \mathrm{mg} / \mathrm{kg})$, anti-cytokine biologics (IL-1, IL- 6 , and TNF- $\alpha$ ), potent immunesuppressor such as cyclophosphamide and plasmapheresis. ${ }^{122)}$ These treatments can induce eventual defervescence but have a limited effect on preformed aneurysms and progression of CALs since the drugs cannot control the etiological substances, and ongoing inflammation of arteritis is dependent on the immune system of the patients. ${ }^{56}$ )

According to reported cases, most patients with MIS-C are treated with IVIG and/or corticosteroids. The treatment policy is based on the hypothesis that the pathophysiological characteristics of MIS-C are related to a hyperinflammation which are similar those of KD. ${ }^{123)}$ The IVIG and/or corticosteroids are effective on reducing of disease severity in a majority of patients although a small part of patients has fatal outcomes, and as with $\mathrm{KD}$, some severely affected patients show an initial therapy nonresponsiveness and are needed additional immune modulators such as biologics and immune suppressants used in $\mathrm{KD}$ and other immune-mediated diseases. ${ }^{124,125)}$ As previously discussed, the intensity of systemic inflammation in the acute febrile stage of KD and MIS-C increases to a peak stage, and tissue cell injury might begin before the peak stage. Thus, early enough dose of immune modulators before the peak stage might be effective in reducing morbidity and preventing tissue cell injuries. This treatment policy has been recommended by experts on rheumatologic diseases including severe JIA, SLE, and MAS. ${ }^{126}$ Also, intensive supportive therapy, including maintenance of fluid-electrolyte balance, inotropic drugs, anticoagulation therapy, mechanical ventilation, and extracorporal membrane oxygenation, is crucial for severely affected patients with COVID-19 or MIS-C.

\section{Conclusions}

The features of severe COVID-19, KD, and MIS-C discussed here are summarized in Table 1. Patients with infectious diseases or infection-related immune-mediated diseases, including COVID-19, KD, and MIS-C, present with various phenotypes. The clinical manifestations of COVID-19, KD, and MIS-C differ, but severe cases share similar clinical and laboratory findings such as a protracted clinical course, multiorgan involvement, and biomarker activation. Near-identical immune markers in the adaptive and innate systems are activated in all diseases. These findings suggest that the immunopathogenesis is similar among these diseases, and a common control system of the host might act against the insult of each.

The etiology and pathophysiology of most human diseases,

Table 1. Features of severe COVID-19, KD, and MIS-C in children

\begin{tabular}{llll}
\hline & \multicolumn{1}{c}{ Severe COVID-19 } & \multicolumn{1}{c}{ KD } & MIS-C \\
\hline Age in predominance & Older children (>5 yr) & Younger children (0-4 yr) & Older children (>5 yr) \\
Male/female ratio & Relatively even & Male predominance ( 1.5:1) & Relatively even \\
Geographic predominance & All around the world & East Asia & Europe, US \\
Clinical findings & Fever, pneumonia & Fever, diagnostic signs & Fiver, Gl symptoms, hypotension, KD-like signs \\
Major complications & ARDS & Giant aneurysm & Refractory shock \\
Laboratory findings & Activated biomarkers in all innate and adaptive immune systems and those associated with affected organs \\
Causal pathogens & SARS-CoV-2 & Strains in microbiota & Strains in microbiota or SARS-CoV-2 \\
Etiological substances & A variety of substances derived from initially infected cells (the focus) and those from injured target cells \\
Main target cells & Lung cells & Coronary artery cells & Intestinal cells or cardiac cells \\
Pathogenesis & A hyperinflammation between etiological substances and corresponding immune cells and immune proteins \\
Diagnosis & PCR, paired serologic test & Clinical signs, laboratory findings & Clinical signs, laboratory findings \\
Treatment & CS, antivirals, biologics, IVIG & IVIG, Cs, biologics & IVIG, Cs, biologics \\
\hline
\end{tabular}

COVID-19, coronavirus disease 2019; KD, Kawasaki disease; MIS-C, multisystem inflammatory system in children; GI, gastrointestinal; ARDS, acute respiratory distress syndrome; SARS-Co-V-2, severe acute respiratory syndrome coronavirus-2; PCR, polymerase chain reaction; Cs, corticosteroids; IVIG, intravenous immunoglobulin. 
including KD and MIS-C, remain unknown. Although etiological agents have been discovered for some infectious diseases, the pathogenesis of target cell injury is unknown. Here we proposed that every disease has etiologic substances controlled by the host's immune systems (the PHS hypothesis) and the etiological agents of KD and MIS-C are strains of microbiota of the human species. Additionally, etiological substances of severe COVID-19, KD, and MIS-C originate from pathogen-infected cells. Since disease severity depends on the amounts of inflammation-inducing substances and corresponding immune activation in the early disease stage, an early proper dose of corticosteroids and/or IVIG can help reduce morbidity and possibly mortality, even in older patients with underlying conditions. The PHS hypothesis simply provides a notion that the phenotype of human diseases is decided by etiological substances, their target cells in various organs, and the corresponding immune reactions to the substances.

During the ongoing COVID-19 pandemic, clinicians and healthcare providers in developed and developing countries have focused on preventive and therapeutic measures in medical or social circumstances. Among immune modulators, corticosteroids are inexpensive analogue of host-origin cortisol. Corticosteroids have been used for nearly all human diseases, including infectious diseases, immune-mediated diseases, allergic diseases, cancer, and even genetic diseases, and can induce early stabilization of hyperactive immune reactions. We expect our findings to help clinicians treating cases of severe COVID-19, $\mathrm{KD}$, and MIS-C especially in developing countries, where supplies of IVIG and other biologics are insufficient.

\section{Footnotes}

Conflicts of interest: No potential conflict of interest relevant to this article was reported.

Funding: This study received no specific grant from any funding agency in the public, commercial, or not-for-profit sectors.

ORCID:

Kyung-Yil Lee @ https://orcid.org/0000-0001-6510-1580

\section{References}

1. Castagnoli R, Votto M, Licari A, Brambilla I, Bruno R, Perlini S, et al. Severe acute respiratory syndrome coronavirus 2 (SARS-CoV-2) infection in children and adolescents: a systematic review. JAMA Pediatr 2020;174:882-9.

2. Feldstein LR, Tenforde MW, Friedman KG, Newhams M, Rose EB, Dapul $\mathrm{H}$, et al. Characteristics and outcomes of US children and adolescents with multisystem inflammatory syndrome in children (MIS-C) compared with severe acute COVID-19. JAMA 2021;325:1074-87.

3. Lee KY, Rhim JW, Kang JH. Immunopathogenesis of COVID-19 and early immunomodulators. Clin Exp Pediatr 2020;63:239-50.

4. Lee KY. The solution on enigmas in COVID-19: the protein-homeostasis- system hypothesis. J Korean Med Assoc 2020;63:366-72.

5. Riphagen S, Gomez X, Gonzalez-Martinez C, Wilkinson N, Theocharis P. Hyperinflammatory shock in children during COVID-19 pandemic. Lancet 2020;395:1607-8.

6. Feldstein LR, Rose EB, Horwitz SM, Collins JP, Newhams MM, Son MBF, et al. Multisystem inflammatory syndrome in U.S. children and adolescents. N Engl J Med 2020;383:334-46.

7. Toubiana J, Poirault C, Corsia A, Bajolle F, Fourgeaud J, Angoulvant F, et al. Kawasaki-like multisystem inflammatory syndrome in children during the covid-19 pandemic in Paris, France: prospective observational study. BMJ 2020;369:m2094.

8. World Health Organization. Multisystem inflammatory syndrome in children and adolescents with COVID-19 [Internet]. Geneva (Switzerland): World Health Organization; 2020 [cited 2020 Jun 6] Available from: https:/www.who.int/news-room/commentaries/detail/multisysteminflammatory-syndrome-in-children-and-adolescents-with-covid-19.

9. Centers for Disease Control and Prevention. Multisystem inflammatory syndrome in children (MIS-C) associated with coronavirus disease 2019 (COVID-19) [Internet]. Atlanta (GA): Centers for Disease Control and Prevention; 2020 [cited 2020 Jun 6] Available from: https://emergency. cdc.gov/han/2020/han00432.asp.

10. Royal College of Paediatrics and Child Health. Paediatric multisystem inflammatory syndrome temporally associated with COVID-19 (PIMS) - guidance for clinicians [Internet]. London: Royal College of Paediatrics and Child Health; 2020 [cited 2020 Jun 6] Available from: https://www. rcpch.ac.uk/resources/paediatric-multisystem-inflammatory-syndrometemporally-associated-covid-19-pims-guidance.

11. Lee KY, Rhim JW, Kang JH. Kawasaki disease: laboratory findings and an immunopathogenesis on the premise of a "protein homeostasis system". Yonsei Med J 2012;53:262-75.

12. Kawasaki T. Acute febrile mucocutaneous syndrome with lymphoid involvement with specific desquamation of the fingers and toes in children. Arerugi 1967;16:178-222.

13. Shulman ST. Pediatric coronavirus disease-2019-associated multisystem inflammatory syndrome. J Pediatric Infect Dis Soc 2020;9:285-6.

14. Lee KY. A common immunopathogenesis mechanism for infectious diseases: the protein-homeostasis-system hypothesis. Infect Chemother 2015;47:12-26.

15. Lee KY. A unified pathogenesis for kidney diseases, including genetic diseases and cancers, by the protein-homeostasis-system hypothesis. Kidney Res Clin Pract 2017;36:132-44.

16. Dong Y, Mo X, Hu Y, Qi X, Jiang F, Jiang Z, et al. Epidemiology of COVID-19 among children in China. Pediatrics 2020;145:e20200702.

17. Ladhani SN, Amin-Chowdhury Z, Davies HG, Aiano F, Hayden I, Lacy $\mathrm{J}$, et al. COVID-19 in children: analysis of the first pandemic peak in England. Arch Dis Child 2020;105:1180-5.

18. Mehta NS, Mytton OT, Mullins EW, Fowler TA, Falconer CL, Murphy OB, et al. SARS-CoV-2 (COVID-19): what do we know about children? A systematic review. Clin Infect Dis 2020;71:2469-79.

19. Rajapakse N, Dixit D. Human and novel coronavirus infections in children: a review. Paediatr Int Child Health. 2021;41:36-55.

20. Rhim JW, Go EJ, Lee KY, Youn YS, Kim MS, Park SH, et al. Pandemic 2009 H1N1 virus infection in children and adults: a cohort study at a single hospital throughout the epidemic. Int Arch Med 2012;5:13.

21. Rhim JW, Lee KY, Youn YS, Kang JH, Kim JC. Epidemiological and clinical characteristics of childhood pandemic 2009 H1N1 virus infection: an observational cohort study. BMC Infect Dis 2011;11:225.

22. Kim H, Shim JY, Ko JH, Yang A, Shim JW, Kim DS, et al. Multisystem inflammatory syndrome in children related to COVID-19: the first case in Korea. J Korean Med Sci 2020;35:e391.

23. Jain S, Sen S, Lakshmivenkateshiah S, Bobhate P, Venkatesh S, Udani S, et al. Multisystem inflammatory syndrome in children with COVID-19 in Mumbai, India. Indian Pediatr 2020;57:1015-9.

24. Antunez-Montes OY, Escamilla MI, Figueroa-Uribe AF, ArteagaMenchaca E, Lavariega-Sarachaga M, Salcedo-Lozada P, et al. COVID-19 and multisystem inflammatory syndrome in Latin American children: a multinational study. Pediatr Infect Dis J 2021;40:e1-6. 
25. Morris SB, Schwartz NG, Patel P, Abbo L, Beauchamps L, Balan S, et al. Case series of multisystem inflammatory syndrome in adults associated with SARS-CoV-2 infection: United Kingdom and United States, MarchAugust 2020. MMWR Morb Mortal Wkly Rep 2020;69:1450-6.

26. Buonsenso D, Riitano F, Valentini P. Pediatric inflammatory multisystem syndrome temporally related with SARS-CoV-2: Immunological similarities with acute rheumatic fever and toxic shock syndrome. Front Pediatr 2020;8:574.

27. McMurray JC, May JW, Cunningham MW, Jones OY. Multisystem inflammatory syndrome in children (MIS-C), a post-viral myocarditis and systemic vasculitis: a critical review of its pathogenesis and treatment. Front Pediatr 2020;8:626182.

28. Kim GB. Reality of Kawasaki disease epidemiology. Korean J Pediatr 2019;62:292-6.

29. Ae R, Makino N, Kosami K, Kuwabara M, Matsubara Y, Nakamura Y. Epidemiology, treatments, and cardiac complications in patients with Kawasaki disease: the nationwide survey in Japan, 2017-2018. J Pediatr 2020;225:23-29.e2.

30. Kim GB, Eun LY, Han JW, Kim SH, Yoon KL, Han MY, et al. Epidemiology of Kawasaki disease in South Korea: a nationwide survey 2015-2017. Pediatr Infect Dis J 2020;39:1012-6.

31. Maddox RA, Person MK, Kennedy JL, Leung J, Abrams JY, Haberling DL, et al. Kawasaki disease and Kawasaki disease shock syndrome hospitalization rates in the United States, 2006-2018. Pediatr Infect Dis J 2021;40:284-8

32. Kushner HI, Abramowsky CR. An old autopsy report sheds light on a "new" disease: infantile polyarteritis nodosa and Kawasaki disease. Pediatr Cardiol 2010;31:490-6.

33. Lee KY, Han JW, Lee JS. Kawasaki disease may be a hyperimmune reaction of genetically susceptible children to variants of normal environmental flora. Med Hypotheses 2007;69:642-51.

34. Rhim JW, Youn YS, Han JW, Lee SJ, Oh JH, Lee KY. Changes in Kawasaki disease during 2 decades at a single institution in Daejeon, Korea. Pediatr Infect Dis J 2014;33:372-5.

35. Singh S, Vignesh P, Burgner D. The epidemiology of Kawasaki disease: a global update. Arch Dis Child 2015;100:1084-8.

36. Quinn RW. Comprehensive review of morbidity and mortality trends for rheumatic fever, streptococcal disease, and scarlet fever: the decline of rheumatic fever. Rev Infect Dis 1989;11:928-53.

37. Wang A. The changing epidemiology of infective endocarditis: the paradox of prophylaxis in the current and future eras. J Am Coll Cardiol 2012;59:1977-8.

38. Kil HR, Yu JW, Lee SC, Rhim JW, Lee KY. Changes in clinical and laboratory features of Kawasaki disease noted over time in Daejeon, Korea. Pediatric Rheumatol 2017;15:60.

39. Keum SW, Hur SM, Youn YS, Rhim JW, Suh JS, Lee KY, et al. Changes in acute poststreptococcal glomerulonephritis: an observation study at a single Korean hospital over two decades. Child Kidney Dis 2015;19:1127.

40. Rhim JW, Lee YT, Kang HM, Suh JS, Lee KY. Changes in clinical features in Henoch-Schönlein purpura during three decades: an observational study at a single hospital in Korea. Clin Rheumatol 2019;38:2811-8.

41. Tajbakhsh A, Gheibi Hayat SM, Taghizadeh H, Akbari A, Inabadi M, Savardashtaki A, et al. COVID-19 and cardiac injury: clinical manifestations, biomarkers, mechanisms, diagnosis, treatment, and follow up. Expert Rev Anti Infect Ther 2021;19:345-57.

42. Iadecola C, Anrather J, Kamel H. Effects of COVID-19 on the nervous system. Cell 2020;183:16-27.e1.

43. Sellers SA, Hagan RS, Hayden FG, Fischer WA 2nd. The hidden burden of influenza: A review of the extra-pulmonary complications of influenza infection. Influenza Other Respir Viruses 2017;11:372-93.

44. Lee KY. Pediatric respiratory infections by Mycoplasma pneumoniae. Expert Rev Anti Infect Ther 2008;6:509-21.

45. Kobayashi T, Ayusawa M, Suzuki H, Abe J, Ito S, Kato K, et al. Revision of diagnostic guidelines for Kawasaki disease (6th revised edition). Pediatr Int 2020;62:1135-8.

46. McCrindle BW, Rowley AH, Newburger JW, Burns JC, Bolger AF, Gewitz
M, et al. Diagnosis, treatment, and long-term management of Kawasaki disease: a scientific statement for health professionals from the American Heart Association. Circulation 2017;135:e927-9.

47. Lee KY, Oh JH, Han JW, Lee JS, Lee BC. Arthritis in Kawasaki disease after responding to intravenous immunoglobulin treatment. Eur J Pediatr 2005;164:451-2.

48. Lee KJ, Kim HJ, Kim MJ, Yoon JH, Lee EJ, Lee JY, et al. Usefulness of anterior uveitis as an additional tool for diagnosing incomplete Kawasaki disease. Korean J Pediatr 2016;59:174-7.

49. Nomura O, Hashimoto N, Ishiguro A, Miyasaka M, Nosaka S, Oana S, et al. Comparison of patients with Kawasaki disease with retropharyngeal edema and patients with retropharyngeal abscess. Eur J Pediatr 2014;173: 381-6.

50. Capone CA, Subramony A, Sweberg T, Schneider J, Shah S, Rubin L, et al. Characteristics, cardiac involvement, and outcomes of multisystem inflammatory syndrome of childhood associated with severe acute respiratory syndrome coronavirus 2 infection. J Pediatr 2020;224:141-5.

51. Davies P, Evans C, Kanthimathinathan HK, Lillie J, Brierley J, Waters G, et al. Intensive care admissions of children with paediatric inflammatory multisystem syndrome temporally associated with SARS-CoV-2 (PIMSTS) in the UK: a multicentre observational study. Lancet Child Adolesc Health 2020;4:669-77.

52. Kwak JH, Lee SY, Choi JW; Korean Society of Kawasaki Disease. Clinical features, diagnosis, and outcomes of multisystem inflammatory syndrome in children associated with coronavirus disease 2019. Clin Exp Pediatr 2021;64:68-75.

53. Radia T, Williams N, Agrawal P, Harman K, Weale J, Cook J, et al. Multisystem inflammatory syndrome in children \& adolescents (MIS-C): a systematic review of clinical features and presentation. Paediatr Respir Rev 2021;38:51-7.

54. Hoste L, Van Paemel R, Haerynck F. Multisystem inflammatory syndrome in children related to COVID-19: a systematic review. Eur J Pediatr 2021;180:2019-34.

55. Lee KY, Han JW, Hong JH, Lee HS, Lee JS, Whang KT. Inflammatory processes in Kawasaki disease reach their peak at the sixth day of fever onset: laboratory profiles according to duration of fever. J Korean Med Sci 2004;19:501-4.

56. Seo YM, Kang HM, Lee SC, Yu JW, Kil HR, Rhim JW, et al. Clinical implications in laboratory parameter values in acute Kawasaki disease for early diagnosis and proper treatment. Korean J Pediatr 2018;61:160-6.

57. Han JW, Oh JH, Rhim JW, Lee KY. Correlation between elevated platelet count and immunoglobulin levels in the early convalescent stage of Kawasaki disease. Medicine (Baltimore) 2017;96:e7583.

58. Kobayashi T, Inoue Y, Takeuchi K, Okada Y, Tamura K, Tomomasa T, et al. Prediction of intravenous immunoglobulin unresponsiveness in patients with Kawasaki disease. Circulation 2006;113:2606-12.

59. Hwang JY, Lee KY, Rhim JW, Youn YS, Oh JH, Han JW, et al. Assessment of intravenous immunoglobulin non-responders in Kawasaki disease. Arch Dis Child 2011;96:1088-90.

60. Han HY, Park KC, Yang EA, Lee KY. Macrolide-resistant and macrolidesensitive Mycoplasma pneumoniae pneumonia in children treated using early corticosteroids. J Clin Med. 2021;10:1309.

61. Matthay MA, Zemans RL, Zimmerman GA, Arabi YM, Beitler JR, Mercat A, et al. Acute respiratory distress syndrome. Nat Rev Dis Primers 2019;5:18.

62. Lee KY. Pneumonia, acute respiratory distress syndrome, and early immune-modulator therapy. Int J Mol Sci 2017;18:388.

63. Lee KY, Rhim JW, Kang JH. Hyperactive immune cells (T cells) may be responsible for acute lung injury in influenza virus infections: a need for early immune-modulators for severe cases. Med Hypotheses 2011;76:649.

64. Borczuk AC. Pulmonary pathology of COVID-19: a review of autopsy studies. Curr Opin Pulm Med 2021;27:184-92.

65. Malloy S, Wang Y. A review on histotechnology practices in COVID-19 pathology investigations. J Histotechnol 2020;43:153-8.

66. Lee KY. New insights for febrile urinary tract infection (acute pyelonephritis) in children. Child Kidney Dis 2016;20:37-44. 
67. Komarova N, Barkova D, Kuznetsov A. Implementation of highthroughput sequencing (HTS) in aptamer selection technology. Int J Mol Sci 2020;21:8774.

68. Kim SY, Yi DY. Components of human breast milk: from macronutrient to microbiome and microRNA. Clin Exp Pediatr 2020;63:301-9.

69. De Filippo C, Di Paola M, Giani T, Tirelli F, Cimaz R. Gut microbiota in children and altered profiles in juvenile idiopathic arthritis. J Autoimmun 2019;98:1-12.

70. Jamshidi P, Hasanzadeh S, Tahvildari A, Farsi Y, Arbabi M, Mota JF, et al. Is there any association between gut microbiota and type 1 diabetes? A systematic review. Gut Pathog 2019;11:49.

71. Esposito S, Polinori I, Rigante D. The gut microbiota-host partnership as a potential driver of Kawasaki syndrome. Front Pediatr 2019;7:124.

72. Kaneko K, Akagawa S, Akagawa Y, Kimata T, Tsuji S. Our evolving understanding of Kawasaki disease pathogenesis: role of the gut microbiota. Front Immunol 2020;11:1616.

73. Rhim JW, Kang HM, Han JW, Lee KY. A presumed etiology of Kawasaki disease based on epidemiological comparison with infectious or immunemediated diseases. Front Pediatr 2019;7:202.

74. Onouchi Y. The genetics of Kawasaki disease. Int J Rheum Dis 2018; 21:26-30.

75. Wopereis H, Oozeer R, Knipping K, Belzer C, Knol J. The first thousand days: intestinal microbiology of early life: establishing a symbiosis. Pediatr Allergy Immunol 2014;25:428-38.

76. Fallani M, Young D, Scott J, Norin E, Amarri S, Adam R, et al. Intestinal microbiota of 6-week-old infants across Europe: geographic influence beyond delivery mode, breast-feeding, and antibiotics. J Pediatr Gastroenterol Nutr 2010;51:77-84.

77. Harusato A, Chassaing B. Insights on the impact of diet-mediated microbiota alterations on immunity and diseases. Am J Transplant 2018; 18:550-5.

78. Korpela K, de Vos WM. Antibiotic use in childhood alters the gut microbiota and predisposes to overweight. Microb Cell 2016;3:296-8.

79. Karthikeyan G, Guilherme L. Acute rheumatic fever. Lancet 2018;392: 161-74.

80. Roberts AL, Connolly KL, Kirse DJ, Evans AK, Poehling KA, Peters TR, et al. Detection of group A Streptococcus in tonsils from pediatric patients reveals high rate of asymptomatic streptococcal carriage. BMC Pediatr 2012;12:3.

81. Osterlund A, Engstrand L. An intracellular sanctuary for Streptococcus pyogenes in human tonsillar epithelium: studies of asymptomatic carriers and in vitro cultured biopsies. Acta Otolaryngol 1997;117:883-8.

82. Di Renzo L, Gualtieri P, Pivari F, Soldati L, Attinà A, Cinelli G, et al. Eating habits and lifestyle changes during COVID-19 lockdown: an Italian survey. J Transl Med 2020;18:229.

83. Ruiz-Roso MB, de Carvalho Padilha P, Mantilla-Escalante DC, Ulloa N, Brun P, Acevedo-Correa D, et al. COVID-19 confinement and changes of adolescent's dietary trends in Italy, Spain, Chile, Colombia and Brazil. Nutrients 2020;12:1807.

84. Zindel J, Kubes P. DAMPs, PAMPs, and LAMPs in immunity and sterile inflammation. Annu Rev Pathol 2020;15:493-518.

85. Gong T, Liu L, Jiang W, Zhou R. DAMP-sensing receptors in sterile inflammation and inflammatory diseases. Nat Rev Immunol 2020;20:95112.

86. Vabret N, Britton GJ, Gruber C, Hegde S, Kim J, Kuksin M, et al. Immunology of COVID-19: current state of the science. Immunity 2020; 52:910-41.

87. Perico L, Benigni A, Casiraghi F, Ng LF, Renia L, Remuzzi G. Immunity, endothelial injury and complement-induced coagulopathy in COVID-19. Nat Rev Nephrol 2021;17:46-64.

88. Alkam T, Nabeshima T. Molecular mechanisms for nicotine intoxication. Neurochem Int 2019;125:117-26.

89. Jesulola E, Micalos P, Baguley IJ. Understanding the pathophysiology of depression: From monoamines to the neurogenesis hypothesis model: are we there yet? Behav Brain Res 2018;341:79-90.

90. van der Poll T, Opal SM. Pathogenesis, treatment, and prevention of pneumococcal pneumonia. Lancet 2009;374:1543-56.
91. Short KR, Kroeze EJ, Fouchier RA, Kuiken T. Pathogenesis of influenza induced acute respiratory distress syndrome. Lancet Infect Dis 2014;14: 57-69.

92. Ulrich H, Pillat MM, Tárnok A. Dengue fever, COVID-19 (SARSCoV-2), and antibody-dependent enhancement (ADE): a perspective. Cytometry A 2020;97:662-7.

93. Kang HM, Choi EH, Kim YJ. Updates on the coronavirus disease 2019 vaccine and consideration in children. Clin Exp Pediatr 2021;64:328-38.

94. Polack FP, Thomas SJ, Kitchin N, Absalon J, Gurtman A, Lockhart S, et al. Safety and efficacy of the BNT162b2 mRNA Covid-19 vaccine. N Engl J Med 2020;383:2603-15.

95. Weisberg SP, Connors TJ, Zhu Y, Baldwin MR, Lin WH, Wontakal S, et al. Distinct antibody responses to SARS-CoV-2 in children and adults across the COVID-19 clinical spectrum. Nat Immunol 2021;22:25-31.

96. Yang HS, Costa V, Racine-Brzostek SE, Acker KP, Yee J, Chen Z, et al. Association of age with SARS-CoV-2antibody response. JAMA Netw Open 2021;4:e214302.

97. Dinnes J, Deeks JJ, Berhane S, Taylor M, Adriano A, Davenport C, et al. Rapid, point-of-care antigen and molecular-based tests for diagnosis of SARS-CoV-2 infection. Cochrane Database Syst Rev 2021;3: CD013705.

98. Caruana G, Croxatto A, Coste AT, Opota O, Lamoth F, Jaton K, et al. Diagnostic strategies for SARS-CoV-2 infection and interpretation of microbiological results. Clin Microbiol Infect 2020;26:1178-82.

99. Arevalo-Rodriguez I, Buitrago-Garcia D, Simancas-Racines D, Zambrano- Achig P, Campo RD, Ciapponi A, et al. False-negative results of initial RT-PCR assays for COVID-19: a systematic review. PLoS One 2020;15:e242958.

100. Jeon HE, Kang HM, Yang EA, Han HY, Han SB, Rhim JW, et al. Early confirmation of Mycoplasma pneumoniae infection by two short-term serologic IgM examination. Diagnostics (Basel) 2021;11:353.

101. Sun B, Feng Y, Mo X, Zheng P, Wang Q, Li P, et al. Kinetics of SARS$\mathrm{CoV}-2$ specific IgM and IgG responses in COVID-19 patients. Emerg Microbes Infect 2020;9:940-8.

102. Deeks JJ, Dinnes J, Takwoingi Y, Davenport C, Spijker R, Taylor-Phillips $S$, et al. Antibody tests for identification of current and past infection with SARS-CoV-2. Cochrane Database Syst Rev 2020;6:CD013652.

103. Huang AT, Garcia-Carreras B, Hitchings MDT, Yang B, Katzelnick LC, Rattigan SM, et al. A systematic review of antibody mediated immunity to coronaviruses: kinetics, correlates of protection, and association with severity. Nat Commun 2020;11:4704.

104. Ko JH, Müller MA, Seok H, Park GE, Lee JY, Cho SY, et al. Serologic responses of 42 MERS-coronavirus-infected patients according to the disease severity. Diagn Microbiol Infect Dis 2017;89:106-11.

105. Youn YS, Lee KY, Hwang JY, Rhim JW, Kang JH, Lee JS, et al. Difference of clinical features in childhood Mycoplasma pneumoniae pneumonia. BMC Pediatr 2010;10:48.

106. Zilla M, Wheeler BJ, Keetch C, Mitchell G, McBreen J, Wells A, et al. Variable performance in 6 commercial SARS-CoV-2 antibody assays may affect convalescent plasma and seroprevalence screening. Am J Clin Pathol 2021;155:343-53

107. Galipeau Y, Greig M, Liu G, Driedger M, Marc-André Langlois MA. Humoral responses and serological assays in SARS-CoV-2 infections. Front Immunol 2020;11:610688.

108. Lee SM, Kim IS, Lim S, Lee SJ, Kim WJ, Shin KH, et al. Comparison of serologic response of hospitalized COVID-19 patients using 8 immunoassays. J Korean Med Sci 2021;36:e64.

109. Miller JM, Binnicker MJ, Campbell S, Carroll KC, Chapin KC, Gilligan $\mathrm{PH}$, et al. A guide to utilization of the microbiology laboratory for diag. nosis of infectious diseases: 2018 update by the Infectious Diseases Society of America and the American Society for Microbiology. Clin Infect Dis 2018;67:e1-94.

110. Shenoy S. SARS-CoV-2 (COVID-19), viral load and clinical outcomes; lessons learned one year into the pandemic: a systematic review. World J Crit Care Med 2021;10:132-50.

111. Lifshitz MS. Preanalysis. In: McPherson RA, Pincus MR, editors. Henry's clinical diagnosis and management by laboratory methods. 23rd ed. 
Amsterdam: Elsevier Health Sciences; 2017.

112. RECOVERY Collaborative Group, Horby P, Lim WS, Emberson JR, Mafham M, Bell JL, et al. Dexamethasone in hospitalized patients with COVID-19. NEngl J Med 2021;384:693-704.

113. The WHO Rapid Evidence Appraisal for COVID-19 Therapies (REACT) Working Group, Sterne JA, Murthy S, Diaz JV, Slutsky AS, Villar J, et al. Association between administration of systemic corticosteroids and mortality among critically ill patients with COVID-19. A meta-analysis. JAMA 2020;324:1330-41.

114. Saleem A, Akhtar MF, Haris M, Abdel-Daim MM. Recent updates on immunological, pharmacological, and alternative approaches to combat COVID-19. Inflammopharmacology 2021;29:1331-46.

115. Russell CD, Millar JE, Baillie JK. Clinical evidence does not support corticosteroid treatment for 2019-nCoV lung injury. Lancet 2020;395: 473-5.

116. World Health Organization. Corticosteroids for COVID-19. Living Guidance [Internet]. Geneva (Switzerland): World Health Organization; 2020 Sep [cited 2020 Sep 30]. Available from: https://www.who.int/ publications/i/item/WHO-2019-nCoV-Corticosteroids-2020.1.

117. Stockman LJ, Bellamy R, Garner P. SARS: systematic review of treatment effects. PLoS Med 2006;3:e343.

118. Lansbury L, Rodrigo C, Leonardi-Bee J, Nguyen-Van-Tam J, Lim WS. Corticosteroids as adjunctive therapy in the treatment of influenza. Cochrane Database Syst Rev 2019;2:CD010406.

119. Kil HR, Lee JH, Lee KY, Rhim JW, Youn YS, Kang JH. Early corticosteroid treatment for severe pneumonia caused by $2009 \mathrm{H} 1 \mathrm{~N} 1$ influenza virus. Crit Care 2011;15:413.

120. Yang EA, Kang HM, Rhim JW, Kang JH, Lee KY. Early corticosteroid therapy for Mycoplasma pneumoniae pneumonia irrespective of used antibiotics in children. J Clin Med 2019;8:E726.

121. Lee KY, Rhim JW, Kang JH. Early preemptive immune modulators (corticosteroids) for severe pneumonia patients infected with SARSCoV-2. Clin Exp Pediatr 2020;63:117-8.

122. Song MS. Predictors and management of intravenous immunoglobulinresistant Kawasaki disease. Korean J Pediatr 2019;62:119-23.

123. Dove ML, Jaggi P, Kelleman M, Abuali M, Ang JY, Ballan W, et al. Multisystem inflammatory syndrome in children: survey of protocols for early hospital evaluation and management. J Pediatr 2021;229:33-40.

124. Ouldali N, Toubiana J, Antona D, Javouhey E, Madhi F, Lorrot M, et al. Association of intravenous immunoglobulins plus methylprednisolone vs immunoglobulins alone with course of fever in multisystem inflammatory syndrome in children. JAMA 2021;325:855-64.

125. Son MBF, Murray N, Friedman K, Young CC, Newhams MM, Feldstein LR, et al. Multisystem inflammatory syndrome in children: initial therapy and outcomes. NEngl J Med 2021;385:23-34.

126. Henderson LA, Canna SW, Friedman KG, Gorelik M, Lapidus SK, Bassiri $\mathrm{H}$, et al. American College of Rheumatology clinical guidance for multisystem inflammatory syndrome in children associated with SARS-CoV-2 and hyperinflammation in pediatric COVID-19: version 2. Arthritis Rheumatol 2021;73:e13-29.

How to cite this article: Rhim JW, Kang JH, Lee KY. Enigmas in severe COVID-19, MIS-C, and Kawasaki disease. Clin Exp Pediatr 2022;65:153-66. https://doi.org/10.3345/cep.2021.01270 